\title{
The Geographical Mobility, Preferences and Pleasures of Prolific Punters: a Demonstration Study of the Activities of Prostitutes' Clients
}

\author{
by Keith Soothill and Teela Sanders \\ Lancaster University and University of Leeds \\ Sociological Research Online, Volume 10, Issue 1, \\ < http://unw.socresonline.org.uk/10/1/soothill.html> \\ doi:10.5153/sro. 1050
}

Received: 25 Feb 2004 Accepted: 21 Jan 2005 Published: 31 Mar 2005

\begin{abstract}
Clients of prostitutes have been traditionally neglected in the study of prostitution. This demonstration study suggests that the Internet, particularly one prominent website for patrons of commercial sex in Britain, can assist in learning more about the activities of prostitutes' clients, their patterns of behaviour and the organisation of commercial sex in contemporary society. The specific focus here is on the geographical locations of the paid sexual encounters of the ten most prolific authors who contribute to a popular website. It reveals 105 different locations identified in the reports with some punters travelling extensively for their pleasures. The study then focuses on a comparison of the activities of two of these punters showing how they both largely inhabit different worlds of the sex industry but also share some experiences. This paper contributes additional knowledge about prostitution at several levels: first, a microanalysis of a small sample of clients' purchasing patterns highlights the habits of some prolific patrons; second, alongside these patterns, the website offers a window onto the hidden world of prostitution in late modernity which in turn reveals some organisational features of prostitution; and third, the use of the Internet as a qualitative data source is explored.
\end{abstract}

\section{Keywords: Internet Methodology, Computer Mediated Communication, Prostitution, Clients, Punters, Sex Work}

\section{Introduction}

1.1 Following a detailed consideration of the legal and social history of prostitutes' clients, Brooks-Gordon and Gelsthorpe (2003) have emphasised that 'recent legislation has taken a tough line with clients of prostitutes'. Led by the changes to the laws in Sweden which made it an offence to purchase sex from 1999, the public mood has supposedly shifted dramatically in the last two decades and that 'we now see the punter and the pimp aligned as coercive and abusive characters from whom the public should be protected'. A coalescence of the punter and the pimp seems a misleading and potentially dangerous conflation. Such a stereotype - which stems from failing to recognise important distinctions in the sex trade - might well lead to legislation, which could be unnecessarily provocative in relation to the sex industry. In fact, most concern has been about the public face of prostitution and the understandable distaste of street interactions, commonly termed kerb-crawling. As a response, there has been 'increasingly punitive, interventionist policies and strategies' which some commentators (e.g.Barnard, Hart and Church, 2002) have seen as creating a worse situation for the most vulnerable women involved in sex work. While there appears to have been an 'unbridled ethic of sexual consumption' in recent times, with the rise of strip clubs, lap-dancing bars, pornography and prostitution in the USA and Western Europe (Bernstein, 2001), this has been met with the 'problematization of male sexuality' through increasing law enforcement.

1.2 This paper offers three distinct contributions to research on prostitution. First, by concentrating on the habits of a small number of clients, the purchasing patterns, rates of expenditure, geographical mobility and communication networks between male clients are exposed. Second, considering the wider functions of one particular website, there is evidence of a sex work community existing in Britain, not only between purchasers but also providers, therefore providing a glimpse into the way in which prostitution is organised on the Internet. Third, using the Internet as a qualitative data source, with additional ethical implications and data collection nuances, we highlight some methodological issues when collating information of a clandestine activity through a virtual medium. 
1.3 This article is a modest demonstration project, which attempts to show that without a tremendous financial outlay - the present work was not funded by any research grant - one can learn much more about the activities of prostitutes' clients than ever before. The Internet can genuinely inform. While there are implicit and explicit social policy issues in considering men who pay for sex, this research was, in fact, much more motivated by a spirit of enquiry in the 1960s tradition of deviance research (Becker (1963), Lemert (1967) and Matza (1969)) where, as sociologists, we should try to understand, justly appreciate and be intrigued by deviant phenomenon rather than being too anxious to correct or change. The material is presented within the spirit of this tradition.

\section{Men Who Buy Commercial Sex}

2.1 Clients of prostitutes have been traditionally neglected in the study of prostitution (see Finnegan, 1979) and this trend has continued despite the recent growth in studies on prostitution. This is primarily for two reasons. Firstly, women who sell sex rather than their clients have been considered to be 'the problem'. In the collection Sex for Sale, Ronald Weitzer (2000:7) asks 'Where are the men?' highlighting the quintessential bias in public attitudes and cultural definitions of prostitution that results in a lack of research conducted on the purchasers of sex. Secondly, clients have been notoriously difficult to contact. Noted by Monto (2000), who made the most of a captive audience of men attending a 'John's' school for rehabilitation in the USA, this group are notoriously difficult to research because of the problems associated with accessing those who secretly go about their activities and do not want to be identified.

2.2 In Britain the popularity of purchasing sex is difficult to assess. Derived from confidential questionnaires, the National Survey of Sexual Attitudes and Lifestyles (Johnson and Mercer, 2001) reported that 8.9 per cent of men in London between the ages of 16-44 had paid for sex in the last five years, with a nationwide figure of 4.3 per cent ( 1 in 23 men). Calculations of the number of clients can also be made using the estimate of 80,000 sex workers in Britain who are visited by on average 20 clients each week (Kinnell, 2005). Both of these sources suggest that these estimates are conservative and, despite confidential data collection methods, the true extent of the number of men who buy sex is still not accountable, but most probably much higher than these predictions suggest.

2.3 Recently, the typical client has been profiled at an average age of 30 years, married, in full-time employment and without criminal convictions (Hester and Westmarland, 2004). Wellings et al (1994) reported that as age increases, more men reported visiting sex workers, with 10.3 per cent of the male population aged 45-59 admitting they buy sex. Equally, the habit does not appear to be sporadic or temporary as men were on average involved for ten and a half years.

2.4 Motivations for purchasing sex have often been the foci of studies (McKeganey, 1994). Xantidia and McCabe (2000) interviewed 66 clients from brothels in Melbourne, Australia and found one subset of men were motivated by the need for intimacy while another group explained their behaviour by the need for novelty and variety in sexual encounters. Monto (2000) found that college graduates were more likely to seek the excitement of illicit sex, while non-graduates are more likely to report difficulties in forming conventional relationships. Research suggests that men seek commercial sex not only for their sexual needs. From interviews with 30 men who defined themselves as regular users, Holzman and Pine (1982) found that men were attracted to prostitution often because of the need for companionship or what Lever and Dolnick (2000:86) have termed the 'illusion of intimacy'. The role of the emotional experience in the commercial transaction for the purchaser is also emphasised by Plumridge et al (1997) who also describe how a subset of clients they interviewed were convinced that even when paying for sex there was a mutual exchange of emotional and sexual pleasure.

2.5 Drawing on accounts from sex workers, Vanwesenbeeck et al (1993) distinguishes a three-pronged typology of male clients: the 'business-type' who approach the transaction as if it were a business deal; the 'romantic/friendship-type' motivated by the need for a relationship with a worker; and the 'misogynist-type' that sort to control women through exerting power in the sexual interaction. In Glasgow, McKeganey and Barnard (1996) interviewed 146 clients (most of whom visited the street market) and found that some men were attracted to prostitution because of its deviant nature, it enabled them to have sex with a range of different women and limited the emotional experience of the sexual encounter.

2.6 One point of clarification when considering the motivations of clients is that the street and the indoor markets (such as escorting) offer different types of services and experiences. For example, Lever and Dolnick found that 'call girls' engaged in long term commercial relationships with clients despite their marital status. As Jordan (1997) also concludes from clients in New Zealand, the empirical findings suggest there are various reasons why men seek commercial sex depending on their personal situation and their ability to meet their needs through conventional sexual relationships.

2.7 Studies of male clients have often concentrated on 'risky' behaviours in relation to sexual health, 
particularly HIV transmission (Barnard et al, 1993;Gibbens and Silberman, 1970), and violent behaviour (Faugier and Sargent, 1996;McKeganey and Barnard, 1996). Research has challenged the notions that male clients are more likely to accept rape myths (beliefs that justify sexual violence towards women) than non-clients. Monto and Hotaling (2001) administered a survey to 700 men who had been arrested for prostitution offences and found that in general men who seek out prostitutes do not hold views that support violence against sex workers. In trying to dispel the stereotypes, Hilary Kinnell, a national spokesperson on UK sex work policy comments: 'clients, far from being a tiny minority of men, with abnormal desires and predilections for violence, are a substantial subsection of the male population, broadly representative of most demographic variables with fairly mundane reasons for engaging in commercial sex, and are rarely violent' (2005). What can be taken from this snapshot of empirical studies is that the men who engage in commercial sex are not extra-ordinary in any way but appear to be a cross section of the population with no outstanding differences from men who do not purchase sex.

\section{The Internet and Prostitution}

3.1 Although not exhaustive, it is worth highlighting some commentaries on the relationship between prostitution and the Internet. The rise of the Internet and computer mediated communication has been linked to wider issues of exploitation, physical and sexual abuse, child pornography and trafficking of vulnerable adults. This has led some commentators such as Hughes (2001) to connect the rise of the use of the virtual arena for organising prostitution as a continuation of 'commercial voyeurism' that serves only to normalise exploitation and violence towards women. However, the vile accounts of men picking up young girls for prostitution and pornography that Hughes exposes cannot be equated with the sex work community that is discussed in this paper. The uses of the Internet for prostitution are as diverse as the people who are involved in selling and buying sex.

3.2 In general, websites have changed the face of the punting experience. Previously, looking for and purchasing commercial sex was an isolating and independent activity where men did not communicate about their sexual behaviour. This was because of the taboo surrounding prostitution, the stigma attached to a sexually deviant act, and also because the majority of clients are involved in long-term relationships. As Sharpe and Earle (2003:37) demonstrate in their study, 'social relationships involved in paying for sex are being transformed by the Internet'. Identities are solidified on message boards, information is freely exchanged and meetings take place (between clients as well as with sex workers) in the real-world.

3.3 The changing social relationships have enabled some sex workers to become active business entrepreneurs. O'Neill (2001p.150) surmises 'prostitutes can tempt their customers much more effectively in cyberspace than by paying for advertising space in small ads, telephone cards and contact magazines'. The Internet provides efficient, effective and safer means of attracting clients and negotiating services (Sanders, 2005). However, Sharpe and Earle (2003) observed the same website that this paper is based on and take a different view on what they term 'cyberwhoring' and 'cyberpunting'. Although they recognise that 'cyberspace offers prostitutes a new opportunity for representation' (p. 41), the limitations of their virtual observations leads them to conclude that 'cyberspace has further empowered the men who pay for sex through the creation of a space which allows men to share good and bad experiences of punting'. From our analysis the website in question is a highly interactive mode of communication, not only a space for men to write (explicitly) about their sexual encounters, but where sex workers and clients interact, debate and discuss commercial sex. Sex workers are active on the site and often encourage clients to write reports about their services. Also, the field reports that do not necessarily treat women as commodities, are an important source of regulating sexual behaviour (especially condom use, what is and is not acceptable), social etiquette and the rules of negotiation, as well as the price code (seeSanders, 2004). This study breaks with a tradition in this area of research that focuses on the motivations of why men buy sex to instead look at patterns of behaviour, particularly in relation to men who engage in a high level of purchasing across a range of sex markets and geographical locations. This study looks beyond the surface of the website to tentatively explore the patterns of the prolific punters and how their behaviour in the online community reflects wider aspects of the social organisation of online prostitution.

\section{The Study}

4.1 The banner headline of the website on which this study is based, describes itself as 'The Online Community for Patrons and Providers of Adult Personal Services in the UK'. The site was created to facilitate the exchange of information on prostitution in the UK. While the site provides various kinds of information, the main focus is the provision of reviews of encounters with 'working girls' (this term is used by both male and female contributors) and the opportunity for readers to submit their own 'field reports' (FRs). The site first went online in January 1999 and claims the notice of two leading newspapers - '...the most successful of the prostitute-reviewing Internet sites' (London Evening Standard) and '...a fantastically detailed piece of research' (The Times). 
4.2 The scale of the enterprise is enormous. The Field Report Statistics note, for instance, that 'as of 19:49 GMT $13^{\text {th }}$ June 2003 ' (the date on which the field reports for this study were collated), 'there are 23510 Field Reports online.' The site reports that 'there are 6505 registered and verified Field Report Authors'. In fact, it further reports that there are 83 authors with 20 or more reports ('They represent 1.27 per cent of the registered authors, but have contributed 10.91 percent of the active Field Reports.').

4.3 The website is not only for purchasers as the emphasis is increasingly on facilitating communication between interested parties. Aside from the field reports, there is an announcements board for women to advertise their services including a 'tour calendar' where sex workers can advertise their dates and locations. This is accompanied by a 'service providers database' which acts in a similar fashion to the classified personal adverts in a newspaper. In addition, resources have been written for 'hobbyists' such as a guide to saunas and massage parlours and details on exactly what to expect and how to behave when visiting indoor establishments. There are also web links to sexual health support services (for women and men), information on sexual health, and legal information.

4.4 One of the most popular facilities on this website is the lively message board that is a constant source of interactive chatting amongst men and women. One of the authors (TS) has observed the message board over several years and has noted how the topics are varied and broad and do not focus only on the sex industry (see Sanders, 2005). Anyone can read the message board as a 'lurker', but to become an active contributor, individuals must register. There are specific 'board rules' that regulate the type of information and comments that are acceptable as well as the tone and purpose of the board. There is a group of moderators who check messages are appropriate. Anyone who sends inflammatory messages, or comments on a topic that is considered 'off-limits' (such as 'posting or requesting information about underage sex workers') is immediately struck off.

4.5 Overall, the website exists because there is a prolific culture of sharing amongst the contributors. For the women who market their businesses, the advantages are obvious. For the men, who post their accomplishments and engage in (most probably) secret communication with fellow clients, the attractions are more complex.

\section{The Data}

5.1 This study considers the top ten authors in terms of the number of Field Reports submitted. This paper focuses on all the reports deposited on the website, by the ten most prolific authors. It considers (1) the main geographical locations of these top ten punters and (2) a comparison of the activity profiles of two of these prolific punters, probing their preferences and pleasures. These ten punters had by 13 June 2003 produced 660 field reports. However, also by this date 112 of these reports had been withdrawn from the site and not available for detailed perusal. Reports are withdrawn for three main reasons - (1) because allegedly the 'lady has retired or moved on' [53]; (2) because the lady or the establishment 'requested all her reports removed' [22]; or (3) because the 'establishment closed down' [21] - thus largely reflecting labour turnover or market conditions. However, five others were withdrawn at the 'author's request', and nine more were on the basis of 'dishonest FR [field report] activity by lady/establishment'. This monitoring activity on behalf of the site thus helps to validate the surviving entries. Finally, two reports were eliminated from the study, simply because they were duplicate entries. This suggests the Field Reports are subject to monitoring and assessment in order to give credibility to the reports and establish accurate and useful information for others.

5.2 This paper considers the 649 reports (that is, excluding the 'dishonest' and duplicate reports), which were available for analysing the geographical mobility of these top ten punters in seeking their pleasures. The Field Reports follow a similar format. Each report is headed with the working name of the sex worker and the town, the Field Report number and the date that the report was posted on the site. There is systematic information which gives the author of the report, the date of the encounter, the location, the time spent and the price. The encounter is described under three headings - 'Her Place', 'Description' and 'Comments'. The report concludes with two questions - 'Recommended?' and 'Would you return?' - to which the author responds either yes or no to each question. It is reported on the site that 'The lady was Not Recommended in $9.31 \%$ of the Field Reports'.

\section{Ethics and the Internet}

6.1 Before the results of this microanalysis are presented, it is important to discuss some poignant issues regarding the type of information that has been collected from the Internet, how it has been collected and various ethical implications when using a virtual source. The barriers of conventional research have certainly been overcome by using an Internet site that provides a window into the previously undocumented world of so many male clients. Indeed, the Internet has facilitated a new virtual community of sex workers, organisers and patrons who were not previously in contact in such a free flowing space before the Internet 
became readily accessible. In areas of deviant and difficult to access populations, research horizons have been stretched by the asynchronous nature of cyberspace and as Hine (2000) suggests, the reluctance and suspicion of using computer mediated communication in social research is slowly subsiding. Yet as Illingsworth (2001) and DiMarco and DiMarco (2003) have described in detail, with these new opportunities come moral, ethical and practical dilemmas for the researcher.

6.2 No permission was gained from those who organise the site, or indeed the ten prolific punters on which this paper is written. This may appear striking in the light of the standard expectations and practice of ethical social science research; especially in the area of informed consent (see British Sociological Associationguidelines). Yet in terms of the Internet as a data collection resource, Marx (1998:172) comments 'conventional principles offer no criteria for deciding if a given means of data collection is ethically acceptable'. This train of thought is continued by Illingsworth (2001) who problematises the 'transference of existing methodological frameworks to an online setting'. Cavanagh (1999) argues that because the very nature of chatrooms is that people may not be who they say they are, any notions of informed consent would be phony and meaningless.

6.3 There are other considerations in terms of conducting ethnographic research in an environment that is neither tangible nor accountable. For instance, conventional methods of establishing a bona fide status as a researcher are not straightforward on the Internet, and creating relationships online (which often move offline) are subject to different types of constraints, suspicions and expectations (Sanders, 2005). What seems to be at the heart of this debate, and indeed our own data collection, is what material is considered public and what is considered private. As Hine and Eve (1998) have described, privacy on the Internet is complex, and there is a case for claiming a form of 'situated privacy' that takes into account the purposes of the website and the rules of the social group. As with real-world ethnographic encounters, this research has abided by the rules of the group that has been studied, and has not put individuals in a position that could cause them harm or disruption.

6.4 Although Fox and Roberts (1999:651) argue that researchers should be mindful of the difference between Internet information 'that is publicly accessible and that which is publicly disseminated', the use of data without specific permission is defensible. First, the information is public and accessible to anyone. The open status of the website and all information that is posted is frequently acknowledged on the message board with the expectation that journalists, police authorities and Home Office researchers are frequent 'lurkers'. Second, there is no way of identifying the case studies in this paper as they all adopt pseudonyms. Also, remaining anonymous and taking steps to protect their own identity is a defining feature of the sex industry. Individuals have invariably given considerable thought to the issue of anonymity before contributing to a public forum about such a private act.

6.5 What about the reliability of the field reports? It may well be feasible that the sexual encounters, prices, and places detailed in each of the 649 reports could be fabricated. This charge could also be made to any qualitative data that is collected from individuals and there seems no reason why the written word should be doubted more than the spoken. This possibility of the field reports being the product of imagination or exaggeration has been dispelled in the minds of the authors because of various safety mechanisms that are built into the website.

6.6 First, the ten prolific punters hold a high profile on the website and therefore making up stories about sexual encounters would jeopardise their reputation and status that invariably accompanies such public proliferation of sexual activities. Also, as stated by Mann and Stewart (2000:210), there is much less divergence between self-presentation in real-time relationships than those presented through online mediums. Second, many of the women who are written about in the field reports are also well-known contributors to the site. For instance, women can comment on the field reports and they are often discussed between providers and purchasers on the message board. The owner of the site provides a facility where people can request the deletion or modification of a field report through a feedback form, suggesting that if something is untrue, it could be removed. In the past it has been observed (see Sanders, 2005) how the moderators and controllers of the websites have rejected field reports that have been found to be exaggerated, rude or distasteful in order to maintain a degree of integrity about the service.

6.7 Third, it must be argued that the spirit of the field reports is of altruistic sharing of precious information that is used by other 'hobbyists' to make decisions about who to visit and how to spend their cash. Moreover, there would be little to gain from posting false reports because there are many ways the poster could be found out and banished from a site that is only useful if the information is honest and up-to-date. The interactions reported on the website, especially the field reports, are snapshots of real encounters that actually take place between people who, in some form, are 'known' by participants. Therefore as Hine (2000) states, just because interactions take place in a virtual arena, 'cyberspace is not to be thought of as a space detached from any connections to 'real life' and face-to-face interaction'. Therefore, a culture of exaggerated egos and sexual exploits is discouraged and would only be met with rejection from other board 
members.

\section{Results}

\section{Geographical mobility}

7.195 different towns and cities are identified as the locations among the 'field reports' submitted by these ten prolific authors. In addition, there are 10 rather wider areas identified - Norfolk [1 report], North East [1], North West [1], West Midlands [1] and six areas of London (Central London [6], East London [15], London [1], North London [2], South London [6], South East London [1]). This produces a total of 105 different locations identified in the reports although some of the towns and cities will be located in the 10 wider areas identified.

Table 1: Range of locations

\begin{tabular}{|c|c|c|c|c|}
\hline & $\begin{array}{l}\text { No. of reports } \\
\text { (incl. withdrawn) }\end{array}$ & $\begin{array}{l}\text { No. of } \\
\text { locations }\end{array}$ & $\begin{array}{l}\text { Main location } \\
\text { (and no. of reports) }\end{array}$ & $\begin{array}{l}\text { Second } \\
\text { location } \\
\text { (and no. of } \\
\text { reports) }\end{array}$ \\
\hline Guitarist & 88 & 14 & Manchester (46) & Crewe (17) \\
\hline Tim & 70 & 18 & Soho (31) & $\begin{array}{l}\text { Manchester } \\
\text { (13) }\end{array}$ \\
\hline Banging Man & 66 & 20 & $\begin{array}{l}\text { Durham (10); Leeds } \\
\text { (10); Newcastle (10) }\end{array}$ & - \\
\hline Cony & 99 & 11 & Brighton (58) & Crawley (15) \\
\hline Johnno & 62 & 12 & Manchester (45) & Preston (5) \\
\hline Xizzy & 56 & 19 & Manchester (15) & $\begin{array}{l}\text { Nottingham } \\
\text { (11) }\end{array}$ \\
\hline Pulsator & 50 & 18 & Belfast (24) & $\begin{array}{l}\text { Edinburgh } \\
\text { (8) }\end{array}$ \\
\hline Hornyboy & 55 & 5 & Manchester (46) & Wigan (4) \\
\hline Sharpshooter3 & 56 & 20 & Horley (13) & $\begin{array}{l}\text { East } \\
\text { Grinstead } \\
(10)\end{array}$ \\
\hline Slapntickle & 47 & 12 & East London (12) & $\begin{array}{l}\text { Chadwell } \\
\text { Heath (8) }\end{array}$ \\
\hline Total & $649^{*}$ & $\begin{array}{l}105 \\
\text { (total) }^{*}\end{array}$ & & \\
\hline
\end{tabular}

Note: The 'dishonest' and duplicate reports have been removed.

* This figure represents the total number of different locations identified.

7.2 Table 1 shows the number of reports (including those later withdrawn) written by each of these ten top authors, the number of geographical locations they visited for paid sex, and then the number of reports emanating from their two principal locations. These prolific authors may not always write a report on each of their encounters but, nevertheless, Table 1 shows that the activities of these top ten punters are distributed throughout the United Kingdom with four seeming to be principally active in the north-west of England (Guitarist, Johnno, Xizzy and Hornyboy), two in the London area (Tim and Slapntickle), two in the south of England (Cony and Sharpshooter3), one in the north-east of England (Banging Man) and one in Belfast (Pulsator). However, Table 1 shows that these prolific punters are very geographically mobile and tend to meet working girls in a large number of locations.

7.3 In fact, Hornyboy has the fewest with just five locations identified - Manchester [46], Wigan [4], Bolton [2], Bury [2] and Oldham [1] - and contrasts markedly with Sharpshooter3 with 20 locations identified Horley [12], East Grinstead [10], Crawley [8], Lingfield [4], Brighton [3], Eastbourne [3], Reading [2], Woking [2], Aldershot [1], Folkestone [1], Guildford [1], Halland [1], Heathfield [1], Hove [1], Maidenhead [1], Portsmouth [1], Redhill [1], Sittingbourne [1], South East London [1], Wokingham [1]. However, the activities of both these punters are fairly circumscribed - Hornyboy in the north-west of England and Sharpshooter3 in the south of England and the Home Counties. It would be misleading to suggest that these are representative of the prolific punters. Banging Man and Xizzy - with 20 and 19 locations identified 
respectively - represent other patterns.

7.4 Banging Man files reports of his activities in Durham [10], Leeds [10], Newcastle [10], Darlington [7], Middlesborough [5], York [4], Edinburgh [3], Manchester [2], South Shields [2], Stockton [2], Washington [2], Chester-le-Street [1], Derby [1], Garforth [1], Hartlepool [1], North East [1], Scarborough [1],

Sunderland [1], Teesside [1], and Wetherby [1]. While the activities of Banging Man are dispersed venturing into Scotland, the midlands and the north-west - his centre of gravity in the north-east is quite evident.

7.5 The activities of Xizzy are even more dispersed and the locations cited are as follows - Manchester [15], Nottingham [10], Leicester [8], Derby [4], Northampton [3], Brighton [2], Darlington [2], Stansted [1],

Doncaster [1], Glasgow [1], Leeds [1], Liverpool [1], London [1], Mansfield [1], Newcastle [1], Norfolk [1],

Peterborough [1], Southampton [1] and Tamworth [1]. However, close inspection of Xizzy's reports on his activities (for the punting 'career' history below) indicate that five of 'My hotel' encounters actually took place in London. The girls were booked from an agency in the north and travelled down to London from Darlington, Derby, Doncaster, Leeds and Northampton. So, for instance, the first 'date' in Darlington (encounter 22b) takes place in Darlington, while for the second 'date' (encounter 24b), he asks for the same working girl to visit him in his hotel in London. While this point seems to undermine some of the findings in Table 1, this is an unusual arrangement and is rarely the case for the other top punters. Certainly, it is less easy to identify Xizzy's likely home address from this array of towns and cities, but he certainly travels widely for his pleasures. If this were a murder trail rather than a pleasure trail, there would be rich scope for the speculations of psychological profilers as to the location of his address.

7.6 The aim now is to consider in some detail the FRs (field reports) of two of these prolific punters. Xizzy and Tim have been chosen simply for illustrative purposes - in brief, they illustrate different patterns of activity. The other punters may illuminate other patterns, but this is a demonstration rather than a definitive study.

\section{Comparing the activity profiles of Xizzy and Tim}

7.7 There are reports available on 53 of Xzzy's encounters. These reports involve 48 different working girls. His reports on encounters $4 a$ and $14 a$ (see Table 2) involve the same two girls - with the letter 'a' indicating this. Similarly, encounters $22 \mathrm{~b}$ and $24 \mathrm{~b}$ involve the same girls. In brief, six of the encounters involve girls he had seen before.

Table 2: The pattern of Xizzy

\begin{tabular}{|c|c|c|c|c|c|}
\hline Encounter & $\begin{array}{l}\text { Date of } \\
\text { encounter }\end{array}$ & Location & Type & $\begin{array}{l}\text { Cost } \\
\text { (£) }\end{array}$ & $\begin{array}{l}\text { Time } \\
\text { Hrs - } \\
\text { mins }\end{array}$ \\
\hline 1 & $27 / 9 / 00$ & Norfolk & MY HOTEL & 175 & $2 \mathrm{~h}$ \\
\hline 2 & $9 / 10 / 00$ & Nottingham & PARLOUR & 65 & $35 \mathrm{~m}$ \\
\hline 3 & $25 / 11 / 00$ & Manchester & PARLOUR & 50 & $40 m$ \\
\hline $4 a$ & $5 / 1 / 01$ & Leicester & $\begin{array}{l}\text { PARLOUR (2 } \\
\text { girls) }\end{array}$ & 140 & $45 \mathrm{~m}$ \\
\hline 5 & $9 / 1 / 01$ & Tamworth & MY HOTEL & 200 & $2 \mathrm{~h}$ \\
\hline 6 & $23 / 1 / 01$ & Northampton & MY HOTEL & 270 & $3 \mathrm{~h}$ \\
\hline 7 & $2 / 2 / 01$ & Peterborough & MY HOTEL & 170 & $2 \mathrm{~h}$ \\
\hline 8 & $9 / 2 / 01$ & Nottingham & MY HOTEL & 150 & $1 \mathrm{~h}$ \\
\hline 9 & $12 / 2 / 01$ & Southampton & MY HOTEL & 210 & $3 \mathrm{~h}$ \\
\hline 10 & $7 / 3 / 01$ & Leicester & PARLOUR & 70 & $35 \mathrm{~m}$ \\
\hline 11 & $9 / 4 / 01$ & Leicester & PARLOUR & 85 & $1 \mathrm{~h}$ \\
\hline 12 & $26 / 4 / 01$ & Newcastle & HER PLACE & 220 & $2 \mathrm{~h}$ \\
\hline 13 & $8 / 5 / 01$ & Leicester & PARLOUR & 85 & $1 \mathrm{~h}$ \\
\hline $14 a$ & $11 / 5 / 01$ & Leicester & $\begin{array}{l}\text { PARLOUR (2 } \\
\text { girls) }\end{array}$ & 140 & $50 \mathrm{~m}$ \\
\hline 15 & $25 / 5 / 01$ & Nottingham & HER PLACE & 170 & $1 \mathrm{~h} 30 \mathrm{~m}$ \\
\hline 16 & $27 / 6 / 01$ & Liverpool & MY HOTEL & 400 & $4 \mathrm{~h}$ \\
\hline
\end{tabular}




\begin{tabular}{|c|c|c|c|c|c|}
\hline 17 & $20 / 7 / 01$ & Nottingham & PARLOUR & 62 & $40 \mathrm{~m}$ \\
\hline 18 & $1 / 9 / 01$ & Leicester & PARLOUR & 85 & $50 \mathrm{~m}$ \\
\hline 19 & $3 / 9 / 01$ & Nottingham & PARLOUR & 62 & $35 \mathrm{~m}$ \\
\hline 20 & $9 / 9 / 01$ & Brighton & PARLOUR & 100 & $50 \mathrm{~m}$ \\
\hline 21 & $10 / 9 / 01$ & Brighton & PARLOUR & 60 & $40 m$ \\
\hline $22 b$ & $17 / 9 / 01$ & Darlington & HER PLACE & 300 & $3 h$ \\
\hline 23 & $26 / 9 / 01$ & Leicester & PARLOUR & 62 & $45 m$ \\
\hline $24 b$ & $3 / 10 / 01$ & London (Darlington) & ) MY HOTEL & 800 & $12 \mathrm{~h}$ \\
\hline 25 & $15 / 10 / 01$ & Nottingham & HER PLACE & 150 & $1 \mathrm{~h}$ \\
\hline 26 & 24/10/01 & Nottingham & PARLOUR & 50 & $35 \mathrm{~m}$ \\
\hline 27c & $26 / 10 / 01$ & Nottingham & HER PLACE & 60 & $35 m$ \\
\hline 28d & $7 / 1 / 02$ & Derby & HER PLACE & 100 & $1 \mathrm{~h}$ \\
\hline 29c & $7 / 1 / 02$ & Nottingham & HER PLACE & 50 & $30 \mathrm{~m}$ \\
\hline 30 & $4 / 2 / 02$ & Mansfield & MY HOTEL & 700 & $12 \mathrm{~h}$ \\
\hline 31 & $7 / 2 / 02$ & London & MY HOTEL & 600 & $10 \mathrm{~h}$ \\
\hline $32 e$ & $18 / 2 / 02$ & Derby & MY HOTEL & 700 & Overnight \\
\hline 33 & $20 / 2 / 02$ & $\begin{array}{l}\text { London } \\
\text { (Doncaster) }\end{array}$ & MY HOTEL & 700 & Overnight \\
\hline 34 & $26 / 2 / 02$ & Manchester & MY HOTEL & 550 & $5 \mathrm{~h}$ \\
\hline $35 e$ & $27 / 2 / 02$ & Derby & MY HOTEL & 700 & Overnight \\
\hline 36 & $7 / 3 / 02$ & London (Leeds) & MY HOTEL & 700 & Overnight \\
\hline 37d & $14 / 3 / 02$ & London (Derby) & MY HOTEL & 700 & $13 \mathrm{~h}$ \\
\hline 38 & $7 / 5 / 02$ & Manchester & $\begin{array}{l}\text { MY HOTEL (2 } \\
\text { girls) }\end{array}$ & 2000 & $15 \mathrm{~h}$ \\
\hline 39 & $15 / 5 / 02$ & Leicester & PARLOUR & 62 & $40 m$ \\
\hline 40 & $15 / 5 / 02$ & Leicester & PARLOUR & 62 & $40 m$ \\
\hline 41 & $8 / 9 / 02$ & Manchester & PARLOUR & 60 & $30 m$ \\
\hline 42 & $8 / 9 / 02$ & Manchester & PARLOUR & 60 & $30 m$ \\
\hline 43 & $9 / 9 / 02$ & Manchester & PARLOUR & 60 & $30 m$ \\
\hline 44 & $9 / 9 / 02$ & Manchester & PARLOUR & 60 & $30 m$ \\
\hline 45 & $10 / 9 / 02$ & Manchester & PARLOUR & 60 & $30 m$ \\
\hline 46 & $10 / 9 / 02$ & Manchester & PARLOUR & 60 & $30 m$ \\
\hline 47 & $10 / 9 / 02$ & Manchester & PARLOUR & 60 & $30 m$ \\
\hline 48 & $21 / 9 / 02$ & Manchester & PARLOUR & 60 & $30 \mathrm{~m}$ \\
\hline 49 & $21 / 9 / 02$ & Manchester & PARLOUR & 60 & $30 m$ \\
\hline 50 & $21 / 9 / 02$ & Manchester & PARLOUR & 60 & $30 m$ \\
\hline $51 f$ & 16/10/02 & $\begin{array}{l}\text { London } \\
\text { (Northampton) }\end{array}$ & MY HOTEL & 800 & Overnight \\
\hline 52 & $7 / 12 / 02$ & Manchester & PARLOUR & 180 & $1 \mathrm{~h} 30 \mathrm{~m}$ \\
\hline $53 f$ & $8 / 1 / 03$ & Northampton & MY HOTEL & 400 & $4 \mathrm{~h}$ \\
\hline
\end{tabular}

7.8 Xizzy's main location - according to the numbers of reports submitted - is Manchester (15 reports) but fairly closely followed by Nottingham (11 reports) as the second location (see Table 1). In contrast, Tim's main location is much more clearly Soho in London (31 reports) with Manchester (13 reports) as his next popular location. Of the 61 reports of Tim's encounters (see Table 3) only twice do the reports seem to involve the same working girl (encounters 1, 3 and 8; encounters 8 and 55). Excluding the report on the Manchester party, Tim's reports relate to 55 different working girls. The 'Party' in Manchester took place with '7 women and 8 men present - the best ratio l've ever seen for a party' (the latter remark suggests that this was not Tim's first 'party').

7.9 For Xizzy the reports span from September 2000 to January 2003 - hence, on average, Xizzy is submitting two reports of encounters per month; however, the submissions are unevenly distributed over time, for he submits ten reports relating to his activities in Manchester in September 2002 which, if it were a drinking pattern, would be regarded as 'binge drinking'. In fact, if all these reports did, indeed, represent 
the occasions he paid for sex, the activity - on a routine basis - is not all that prolific. However, for Xizzy it is certainly expensive. During a period which approaches two and a half years Xizzy reports that he spent a total of $£ 13,995$ on the encounters which were distributed between 27 in parlours, 19 in his own hotel and seven in the working girl's own place. As there is such a cost difference between meeting a girl in a parlour and in his own hotel, averages become rather misleading - £264 for the mean and £100 for the median. His most expensive encounter was $£ 2000$ spent on having two girls at his hotel in Manchester for 15 hours, while his cheapest encounters were when he spent just $£ 50$ in a parlour in Manchester and, similarly, $£ 50$ on an encounter in 'her place' in Nottingham.

7.10 One can begin to identify whether there has been any change in Xzzy's behaviour over time - does he begin to favour encounters at his hotel more? Does he prefer to travel or does he concentrate more in one area? Contrasting the first 26 reports in Table 2 with the last 26 reports provides some clues. In the first half he visits 13 locations (but half of these reports are either from Leicester [7] or Nottingham [6]), while in the second half he submits reports from only nine locations with half the reports emanating from Manchester. The reports from the 14-day 'binge' in Manchester parlours dominate but there is also a shift towards encounters in 'My hotel' - eight in the first half and eleven in the second half. However, close reading of Xizzy's reports show that they provide just a window on his overall activity. In his report on encounter 46, Xizzy notes, 'I think I have made love to between 200 and 300 women'. There are three possibilities - he is exaggerating the number of women, his 'adventures' started long before he wrote his reports, or there is more concurrent activity than he is reporting upon.

7.11 Xizzy seems generally satisfied with his encounters - in all 53 reports he recommends the working girl and says that he would return. Another feature is that he rarely mentions race, ethnicity or skin colour in his reports. In fact, just in four cases does he do so - 'dark-skinned' (encounter 6 in 'My hotel'); 'half-Asian' (encounter 11 in a parlour); 'olive-skinned' (encounter 25 in 'Her place') and 'Russian' (encounter 31 in 'My hotel'). It seems likely that Xizzy's encounters are predominantly with white British working girls. Tim's world is rather different.

7.12 Tim provides a stark contrast to the activities of Xizzy. His reports span from August 2001 to April 2003 and, on average, Tim is submitting more reports of encounters per month than Xizzy - three rather than two. However, the patterns are rather different in other ways.

\section{Table 3: The pattern of Tim}

\begin{tabular}{llllll}
\hline \multicolumn{2}{l}{ Encounter Date of encounter } & Location & Type & Cost (£) Time \\
Hrs - mins \\
$\mathbf{1 a}$ & $14 / 8 / 01$ & Soho & WALK-UP & 25 & $15 \mathrm{~m}$ \\
$\mathbf{2}$ & $18 / 8 / 01$ & Soho & WALK-UP & 25 & $15 \mathrm{~m}$ \\
$\mathbf{3 a}$ & $28 / 8 / 01$ & Soho & WALK-UP & 25 & $10 \mathrm{~m}$ \\
$\mathbf{4}$ & $24 / 10 / 01$ & Soho & WALK-UP & 30 & $10 \mathrm{~m}$ \\
$\mathbf{5 a}$ & $25 / 10 / 01$ & Soho & WALK-UP & 25 & $20 \mathrm{~m}$ \\
$\mathbf{6}$ & $26 / 10 / 01$ & Redhill & FLAT & 60 & $25 \mathrm{~m}$ \\
$\mathbf{7}$ & $4 / 11 / 01$ & South London & HER PLACE & 60 & $30 \mathrm{~m}$ \\
$\mathbf{8 a}$ & $8 / 11 / 01$ & Slough & HOUSE & 60 & $15 \mathrm{~m}$ \\
$\mathbf{9}$ & $16 / 11 / 01$ & East London & PARLOUR & 30 & $15 \mathrm{~m}$ \\
$\mathbf{1 0}$ & $18 / 11 / 01$ & Soho & WALK-UP & 25 & $5 \mathrm{~m}$ \\
$\mathbf{1 1}$ & $22 / 11 / 01$ & Soho & WALK-UP & 25 & $10 \mathrm{~m}$ \\
$\mathbf{1 2}$ & $6 / 12 / 01$ & South London & PARLOUR & 60 & $20 \mathrm{~m}$ \\
$\mathbf{1 3}$ & $21 / 12 / 01$ & Soho & WALK-UP & 20 & $15 \mathrm{~m}$ \\
$\mathbf{1 4}$ & $27 / 12 / 01$ & Soho & WALK-UP & 25 & $10 \mathrm{~m}$ \\
$\mathbf{1 5}$ & $27 / 1 / 02$ & Brighton & PARLOUR & 60 & $15 \mathrm{~m}$ \\
$\mathbf{1 6}$ & $15 / 2 / 02$ & Brighton & HER PLACE & 50 & $20 \mathrm{~m}$ \\
$\mathbf{1 7}$ & $25 / 2 / 02$ & Soho & WALK-UP & 30 & $15 \mathrm{~m}$ \\
$\mathbf{1 8}$ & $11 / 3 / 02$ & Surbiton & HER PLACE & 60 & $40 \mathrm{~m}$ \\
$\mathbf{1 9}$ & $12 / 3 / 02$ & Soho & WALK-UP & 25 & $15 \mathrm{~m}$ \\
$\mathbf{2 0}$ & $15 / 3 / 02$ & Brighton & PARLOUR & 50 & $25 \mathrm{~m}$ \\
$\mathbf{2 1}$ & $20 / 3 / 02$ & Soho & WALK-UP & 25 & $10 \mathrm{~m}$ \\
& & & & &
\end{tabular}




\begin{tabular}{|c|c|c|c|c|c|}
\hline 22 & $4 / 4 / 02$ & Soho & WALK-UP & 30 & $10 \mathrm{~m}$ \\
\hline 23 & $22 / 4 / 02$ & Soho & WALK-UP & 25 & $15 \mathrm{~m}$ \\
\hline 24 & $28 / 4 / 02$ & Soho & WALK-UP & 25 & $15 \mathrm{~m}$ \\
\hline 25 & $4 / 5 / 02$ & East London & PARLOUR & 60 & $30 \mathrm{~m}$ \\
\hline 26 & $4 / 5 / 02$ & Soho & WALK-UP & 25 & $15 \mathrm{~m}$ \\
\hline 27 & $12 / 5 / 02$ & Oldham & PARLOUR & 65 & $1 \mathrm{~h}$ \\
\hline 28 & $15 / 5 / 02$ & Manchester & PARLOUR & 40 & $30 \mathrm{~m}$ \\
\hline 29 & $17 / 5 / 02$ & Soho & WALK-UP & 25 & $10 \mathrm{~m}$ \\
\hline 30 & 19/5/02 & Manchester & PARLOUR & 40 & $30 \mathrm{~m}$ \\
\hline 31 & $20 / 5 / 02$ & Manchester & PARLOUR & 25 & $30 m$ \\
\hline 32 & 10/6/02 & Soho & WALK-UP & 60 & $10 \mathrm{~m}$ \\
\hline 33 & 23/6/02 & Ilford & PARLOUR & 60 & $30 m$ \\
\hline 34 & 26/6/02 & Manchester & PARLOUR & 50 & $35 \mathrm{~m}$ \\
\hline 35 & 28/6/02 & Manchester & PARTY & 150 & $3 \mathrm{~h} 30 \mathrm{~m}$ \\
\hline 36 & 29/6/02 & Manchester & PARLOUR & 50 & $35 \mathrm{~m}$ \\
\hline 37 & $3 / 7 / 02$ & Soho & WALK-UP & 25 & $15 \mathrm{~m}$ \\
\hline 38 & 10/7/02 & Soho & WALK-UP & 25 & $10 \mathrm{~m}$ \\
\hline 39 & $12 / 7 / 02$ & Central London & HER PLACE & 50 & $30 \mathrm{~m}$ \\
\hline 40 & 19/7/02 & Soho & WALK-UP & 25 & $10 \mathrm{~m}$ \\
\hline 41 & $27 / 7 / 02$ & Hounslow & HER PLACE & 60 & $30 \mathrm{~m}$ \\
\hline 42 & 28/7/02 & Soho & WALK-UP & 30 & $15 \mathrm{~m}$ \\
\hline 43 & $6 / 8 / 02$ & Southall & HER PLACE & 60 & $25 m$ \\
\hline 44 & 29/10/02 & Soho & WALK-UP & 25 & $10 \mathrm{~m}$ \\
\hline 45 & $30 / 10 / 02$ & Tolworth & HER PLACE & 60 & $25 \mathrm{~m}$ \\
\hline 46 & $31 / 10 / 02$ & Soho & WALK-UP & 25 & $10 \mathrm{~m}$ \\
\hline 47 & $1 / 11 / 02$ & Bristol & PARLOUR & 35 & $20 m$ \\
\hline 48 & $14 / 11 / 02$ & Soho & WALK-UP & 30 & $10 \mathrm{~m}$ \\
\hline 49 & $20 / 11 / 02$ & Blackpool & OWN PLACE & 50 & $20 m$ \\
\hline 50 & $21 / 11 / 02$ & Crewe & PARLOUR & 40 & $30 \mathrm{~m}$ \\
\hline 51 & $27 / 11 / 02$ & Soho & WALK-UP & 30 & $10 \mathrm{~m}$ \\
\hline 52 & $20 / 12 / 02$ & Bristol & PARLOUR & 40 & $15 \mathrm{~m}$ \\
\hline 53 & $16 / 1 / 03$ & East London & PARLOUR & 30 & $10 \mathrm{~m}$ \\
\hline 54 & $31 / 1 / 03$ & Soho & WALK-UP & 25 & $10 \mathrm{~m}$ \\
\hline $55 b$ & $5 / 2 / 03$ & Soho & WALK-UP & 25 & $15 \mathrm{~m}$ \\
\hline 56 & $12 / 2 / 03$ & Crewe & PARLOUR & 40 & $30 m$ \\
\hline 57 & $13 / 2 / 03$ & Manchester & PARLOUR & 45 & $15 \mathrm{~m}$ \\
\hline 58 & $14 / 2 / 03$ & Manchester & PARLOUR & 60 & $35 \mathrm{~m}$ \\
\hline 59 & $4 / 3 / 03$ & Soho & WALK-UP & 25 & $10 \mathrm{~m}$ \\
\hline 60 & $8 / 4 / 03$ & Soho & PARLOUR & 60 & $20 m$ \\
\hline 61 & $14 / 4 / 03$ & Soho & WALK-UP & 25 & $10 \mathrm{~m}$ \\
\hline
\end{tabular}

Note: There were three separate entries for the Manchester party but listed as one above.

7.13 Around one-half [30] of Tim's encounters were in Soho walk-ups. Tim's first report describes a 'walk-up with concrete stairs, smelling of piss'. Another 20 encounters are in parlours, whilst the others are variously described - her place [7], flat [1], house [1], own place [1]. The remaining encounter was the 'party' in Manchester.

7.14 Tim spends considerably less on his pleasures than Xizzy. He reports that he spent a total of $£ 2470$ (compared with a total of $£ 13,995$ for Xizzy) on the encounters. His most expensive encounter was $£ 150$ on the 'Party' in Manchester, but all the other encounters were $£ 65$ or below with the cheapest encounter costing $£ 20$ in a Soho 'walk-up' - 'Paid for French and Sex, which was, surprisingly, cheaper here than in any other Soho walk-up l've been in'. The average expenditure per encounter was $£ 40$ (average - mean) or 
7.15 Unlike Xizzy who recommended and would return to all the girls he encountered, Tim would not recommend around one in five of the girls he met and would not return to just over one in three of the girls. It would seem either that Tim is less easy to please than Xizzy or that Tim is experiencing the hazards of a different market. While the possibilities are not mutually exclusive, the likelihood is the latter. Even comparing their respective reactions to the parlours in Manchester does not provide a rigorous comparison, for Tim tended to go to the cheaper parlours than Xizzy. Nevertheless, of the seven encounters in Manchester parlours, Tim recommends all the working girls and would return to all except one ('She's a horny girl, but I did feel short-changed on the time and the lack of a pussy-lick'. Encounter 57).

7.16 The market of the sex industry that Tim largely inhabits has another characteristic that distinguishes him from the sex world that Xizzy inhabits. Race or ethnicity features significantly in Tim's reports - of the 55 working girls (that is, apart those attending the 'Party') for whom there is a report, he mentions their ethnicity or race in almost one-half (27) of the cases - Greek [3], Indian [3], Russian [3], Spanish [3], Czech [2], Malaysian [2], Thai [2], Anglo-Indian [1], Chinese [1], Italian/Spanish [1], Japanese [1], Philippino [1], Polish [1], Thai/Japanese [1], Swedish [1], Swedish/Italian [1]. While there is no information whether these working girls were born in Britain or came from abroad, there is clearly a much greater diversity of background among the working girls that Tim encounters. It could be, of course, that Xizzy simply fails to mentions racial characteristics but this is unlikely. In brief, Tim seems to have entered a world of the sex industry that is rather different.

7.1722 of the 28 different girls encountered by Tim in a Soho walk-up were from a wide variety of ethnic or national backgrounds; in contrast, just five of the remaining 27 girls encountered by Tim in parlours and other venues were so identified. The availability of sex workers from a wide range of nationalities raises questions regarding the ethnic make-up of some parts of the sex industry especially in relation to specific geographical areas. Capital cities have notoriously attracted migrant and immigrant workers and this experience may simply reflect the changing economic labour forces of this illegal economy.

\section{Discussion and Conclusions}

8.1 The starting point of this study was to meet the challenge of McKeganey and Barnard (1996) that 'for the most part men buying sex remain invisible'. The identification of an Internet site with over twenty three thousand Field Reports from clients of prostitutes means that many men buying sex become partly visible. This is essentially a demonstration project and some key methodological decisions were made. It was felt that those who write the most may also provide the most information. For this reason we chose to study the ten most prolific authors on the site. While prolific authors may not equate with the most prolific punters - there will be others who may punt more and write less - these are still men who pay for sex on many occasions.

8.2 There is a danger in seeing these top punters in similar terms. Simon (2001) stresses that 'in contemporary society, prostitution has become a curiously stratified specialized profession' (p.264). In other words, it is argued that different prostitutes occupy different market niches. In contrast, the clients of prostitutes have been neglected in this type of debate. So, for example, we are left wondering do clients of street prostitutes also use the services of escort agencies? Do those who make use of parlours favour purchasing other forms of sexual activity? At present the evidence is largely anecdotal with the media providing some surprises of how wealthy, good-looking and well-connected men, such as the actor, Hugh Grant, may well buy sex on the streets. We can only add to the request for further research on the men involved in prostitution in order to move away from 'a sexual double standard in which women are seen as responsible for male deviance' (Monto, 2000:68).

8.3 Internet sites dedicated to this industry provide some scope for studying the 'client careers' of those who pay for sex. The two case studies of Xizzy and Tim illustrate that these 'careers' can be very different. However, the overlap is as instructive as the difference. While Tim never paid above $£ 65$ - except once - for an encounter, Xizzy, in contrast, paid $£ 2000$ for 15 hours of pleasure with two girls using his hotel room as a base. The exception for Tim was the $£ 150$ he paid to attend a 'party' in Manchester but, interestingly, attending a 'party' was not a venture that there is any evidence that Xizzy experienced. Similarly, while Xizzy never paid less than $£ 50$ for an encounter, Tim routinely paid much less than this amount for his encounters in Soho 'walk-ups' that are just a step or two in both distance and speed from a street encounter. In brief, therefore, Xizzy and Tim seem to live and operate in completely different worlds. However, that would only be half the story.

8.4 The world of the parlour is where they figuratively meet in that both Xzzy and Tim use these venues for sex. Over one-half of Izzy's sexual encounters are in a parlour while around one-third of Tim's encounters are in parlours. So, in that sense, they do use similar establishments. In theory, Manchester was a venue 
when they could have actually met but without realising it. However, in fact, the parlours that Xizzy visited in Manchester were different from those that Tim visited. Nevertheless, they do share the same world in a closer way than one might perhaps have imagined. Interestingly, one of the girls that Xizzy encountered in a Manchester parlour (described as 'a cracking blonde with a very shapely figure and a nice personality to match') is almost certainly one of the girls that Tim 'shagged' at the Manchester 'Party'. Their respective 'binges' brought them that close together. Whether they know each other, have met each other in the realworld, or remain only as virtual identities is not known.

8.5 There are at least two reasons for pursuing a study of deviant activity. We have stressed that this study was undertaken in the spirit of the tradition developed in the 1960s that, as sociologists, we should try to understand, justly appreciate and be intrigued by deviant phenomenon rather than being too anxious to correct or change. In brief, reading the reports of clients' commercial sexual transactions perhaps helps us to understand the neglected world of the clients of prostitutes and the social organisation of contemporary prostitution in Britain.

8.6 This website provides reports of encounters in private space rather than public space. In other words, there are no mentions of street encounters but rather it enters the world of parlours, flats, houses and hotels. In probing the punting 'careers' of Xizzy and Tim, it is clear that clients inhabit various different worlds of the sex industry. Their expenditures and their practices may be vastly different but the rules of engagement and expectations of behaviour are similar, suggesting that in real-world sexual encounters and in the virtual world the punters are part of the same social group that is bound by norms, values and sanctions. For the sociologist, this is intriguing in revealing that the strata among the clients of prostitutes are not as segregated as one might perhaps have expected. But for others with different perspectives the results may have different messages.

8.7 There are some distinct policy implications for some of the observations made in this paper. There are those who might wish to change or police the deviant behaviour exposed on the Internet. For the health 'police' who may be concerned about the transmission of infection or disease, Xizzy and Tim may once again reveal the dangers of a promiscuous society. In truth, reports of unprotected sexual intercourse are rare suggesting that the dangers of unprotected sex are perhaps more likely to be realised among those who don't pay for sex rather than those who do. Furthermore, Internet sites, such as these, provide a mechanism by which these activities can police themselves. There are moral issues to be confronted but the site is an adult site that explicitly rejects child prostitution, derogatory talk about women and distasteful sexual activities Indeed, it asks - 'Have you been offered an underage girl? Report child prostitution - ring Crimestoppers on 0800555111 '. In this instance it may be best just to be intrigued by the phenomenon rather than being too anxious to correct or change.

8.8 There are conclusions that can be drawn from the popularity of the website and the prevalence of the virtual sex work community that suggest a permanent change in the social organisation of prostitution. With policing strategies and local government initiatives set to cleanse the streets, particularly of telephone calling cards in the capital (Hubbard, 2002) and of 'kerb-crawlers' in the suburbs (Brooks-Gordon and Gelsthorpe, 2003;Campbell and Storr, 2001), the Internet will become increasingly popular because of it ability to remain free from censorship and official policing. Legislative changes in other parts of the sex industry have a domino effect on the role of the Internet in organising prostitution. Kilvington, Day and Ward (2001) suggest that 'any reduction in the number of street workers is unlikely to reflect a move out of sex work altogether. It is more probable that both workers and customers have chosen less visible ways of making contact'.

8.9 With imminent changes to the management of prostitution based on the recent Home Office (2004) paper 'Paying the Price: a consultation on prostitution', any authoritarian reorganisation of the sex industry will prompt an increase in the role of the Internet for advertising, negotiating and organising commercial sex. However, in highlighting the increased importance in the role of the Internet in prostitution, we are not suggesting that this should be met with punitive scrutiny from law enforcement agencies where the activities involved are consensual adult interactions. Instead, with observations such as those made in this exploratory study and other virtual-ethnography that has taken place inside the sex industry (Sanders, 2004;Soothill, 2004), we would argue that this virtual space is already actively policed and monitored by those involved in selling and buying commercial sex. Moreover, the regulation of behaviour online transfers to the off-line real-life encounters between men and women, relying on each other to reach their desired goal, usually in a safe and consensual manner.

\section{References}

BARNARD, M., McKEGANEY and LEYLAND, A. 1993. 'Risk behaviours among male clients of female street prostitutes'. British Medical Journal 307: 361-2. 
BARNARD, M., HART, G. and CHURCH, S. (2002) Client violence against prostitute women working from street and off-street locations: a three-city comparison. Violence Research Programme. Research Findings. Swindon: Economic and Social Research Council.

BECKER, H. S. (1963) Outsiders: studies in the sociology of deviance. New York: Free Press.

BERNSTEIN, E. 2001. 'The Meaning of the Purchase: Desire, Demand and the Commerce of Sex'. Ethnography 2: 389-420.

BRITISH SOCIOLOGICAL ASSOCIATION Ethical guidelines (2001) http://www.britsoc.org.uk BROOKS-GORDON, B. and GELSTHORPE, L. (2003) 'Prostitutes' clients, Ken Livingstone and a new Trojan horse', Howard Journal of Criminal Justice , 42, 5 (December), 437-451.

CAVANAGH, A. 1999. 'Behaviour in Public? Ethics in Online Ethnography'. Cybersociology 6.

CAMPBELL, R., \& Storr, M. (2001). Challenging the Kerb Crawer Rehabilitation Programme. Feminist Review, 67, (Spring) 94-108.

DIMARCO, A. and DiMARCO, H. 2003. 'Investigating cybersociety: a consideration of the ethical and practical issues surrounding online research in chat rooms' in Jewkes, Y. (ed.) Dot.Cons. Crime, Deviance and Identity on the Internet. Cullompton: Willan.

FAUGIER, J and SARGENT, F. 1996. 'Boyfriends, Pimps and Clients' in Scambler, G. and Scambler, A. (eds.) Rethinking Prostitution. London: Routledge.

FINNEGAN, F. 1979. Poverty and Prostitution: A Study of Victorian Prostitutes in York . Cambridge: Cambridge University Press.

FOX, N and ROBERTS, C. 1999. 'GPs in cyberspace: the sociology of a 'virtual community". Sociological Review 47: 643-71.

GIBBENS, T and SILBERMAN, M. 1970. 'The Clients of Prostitutes'. The British Journal of Venereal Diseases 36: 113-117.

HESTER, N and WESTMARLAND, N. 2004. 'Tackling Street Prostitution: Towards a Holistic Approach' . London: Home Office.

HINE C. 2000. Virtual Ethnography. London: Sage.

HINE, C. and EVE, J. 1998. 'Privacy in the Marketplace'. Information Society 14: 253-262.

HOLZMAN, H. and PINE, S. 1982. 'Buying Sex: The Phenomenology of Being a John'. Deviant Behaviour 4: 89-116.

HOME OFFICE, 2004. 'Paying the Price:A Consultation Paper on Prostitution' . London: HMSO.

HUBBARD, P. (2002). Maintaining Family Values? Cleansing the Streets of Sex Advertising. Area,34,4, 353-360.

HUGHES, D. 2001. 'Prostitution Online' : http://www.uri.edu/artsci/wms/Hughes/demads.htm.

ILLINGSWORTH, N. 2001. 'The Internet Matters: Exploring the Use of the Internet as a Research Tool'. Sociological Research Online 6: www.socresonline.org.uk.

JOHNSON, A. and MERCER, C. 2001. 'Sexual behaviour in Britain: partnerships, practices and HIV risk behaviour'. Lancet 358: 1835-42.

JORDAN, J. 1997. 'User Pays: Why Men Buy Sex'. Australian and New Zealand Journal of Criminology 30: $55-71$.

KILVINGTON, J., Day, S., \& Ward, H. (2001). Prostitution Policy in Europe: A Time for Change? Feminist Review,67, (Spring) 78-93.

KINNELL, H. 2005. 'Demonizing Clients: How Not to Promote Sex Workers' Safety' in Matthews, R., O'Neill, M. and Campbell, R. (eds.) Prostitution Now. Cullumpton: Willan. 
LEMERT, E. M. (1967) Human Deviance: Social Problems and Social Control . New Jersey: Prentice-Hall.

LEVER, J. and DOLNICK, D. 2000. 'Clients and Call Girls: Seeking Sex and Intimacy' in Weitzer, R. (ed.) Sex for Sale. London: Routledge

MANN, C and STEWART, F(2000) Internet Communication and Qualitative Research: A handbook for Researching Online London, Sage.

MARX, G. 1998. 'An ethics for the new surveillance'. Information Society 14: 171-185.

MATZA, D. (1969) Becoming Deviant. New Jersey: Prentice-Hall.

MCKEGANEY, N. 1994. 'Why do men buy sex and what are their assessments of the HIV related risks when they do?'. AIDS Care 6: 289-301.

MCKEGANEY, N. and BARNARD, M. (1996) Sex Work on the Streets: Prostitutes and their Clients. Buckingham: Open University Press.

MONTO, M. A. (2000) 'Why men seek out prostitutes', in Weitzer, R. Sex for Sale. London: Routledge.

MONTO, M. and HOTALING, N. 2001. 'Predictors of Rape Myth Acceptance Among Male Clients of Female Street Prostitution'. Violence Against Women 7: 275-293 O'NEILL, M. 2001. Prostitution and Feminism. London: Polity Press.

PLUMRIDGE, E., CHETWYND, S.J., REED, A. and GIFFORD, S. 1997. 'Discourses of Emotionality in Commercial Sex'. Feminism and Psychology 7: 165-181.

SANDERS, T. 2004. Sex Work. A Risky Business . Cullompton: Willan.

SANDERS, T. 2005. 'Researching the Online Sex Work Community' in Hine, C. (ed.) Virtual Methods in Social Research on the Internet. Oxford: Berg.

SHARP, K. and EARLE, S. 2003. 'Cyberpunters and cyberwhores: prostitution on the Internet' in Jewkes, Y. (ed.) Dot Cons. Crime, Deviance and Identity on the Internet . Cullompton: Willan.

SIMON, D. R. (2001) 'Prostitution - Female' in Bryant, C. E. (ed.) Encyclopedia of Criminology and Deviant Behavior. Philadelphia: Brunner-Routledge.

SOOTHILL, K. 2004. 'Parlour Games: The Value of An Internet Site Providing Punters' Views of Massage Parlours'. The Police Journal 77: 43-53.

VANSWESENBEECK, I., de GRAFF, R., VAN ZESSEN, G. and STRAVER, C. 1993. 'Protection Styles of Prostitutes Clients: Intentions, behaviour and considerations in relation to AIDS'. Journal of Sex Education Theory 19: 79-92.

WEITZER, R. 2000. Sex for Sale. London: Routledge.

WELLINGS, K., FIELD, J., JOHNSON, A. and WADSWORTH, J. 1994. Sexual Behaviour in Britain . London: Penguin.

XANTIDIA, L. and McCABE, M.P. 2000. 'Personaity Characteristics of Male Clients of Female Commercial Sex Workers IN Australia'. Archives of Sexual Behaviour 29: 165-176. 